\title{
A Pyrolysis Mass Spectrometry Study of Polythiophene - Natural Rubber and Polythiophene - Synthetic Rubber Conducting Polymer Composites
}

\author{
S. Yigit ${ }^{a}$, J. Hacaloglu ${ }^{b}$ U. Akbulut ${ }^{b}$, and L. Toppare ${ }^{c}$ \\ ${ }^{a}$ Roketsan Missiles Ind. Inc. , P.O. Box. 30 Elmadag, 06780 Ankara, Turkey \\ ${ }^{b}$ Department of Chemistry, Middle East Technical University, 06531 Ankara Turkey \\ ${ }^{\mathrm{C}}$ Department of Chemistry, Bilkent University, 06533 Ankara Turkey
}

\begin{abstract}
The thermal behaviors and degradation products of conducting polymer composites prepared by electrooxidation of thiophene using natural rubber or synthetic rubber as the insulating matrix were studied by direct and indirect mass spectrometry techniques. The pyrolysis mass data revealed that a chemical interaction formed between the components of the composites during polymerization. Thermal characteristics of rubbers totally disappeared in the composites indicating presence of some chain scissions leading to degradation of rubbers during electrooxidative polymerization. The multiscan cyclic voltammetry runs showed that polythiophene is also electroactive on the rubber coated metal electrodes, with a sma!l shift in the redox peaks compared to the one on the bare electrode.
\end{abstract}

Key words: pyrolysis mass spectrometry, conducting polymer composites

\section{Introduction}

The electrically conducting polymers such as polypyrrole, polythiophene, polyfuran and polyaniline have been examined for possible electronic and chemical applications[1-2]. However, the use of electrically conducting polymers has been limited in the past by problems associated with poor environmental satiability and/or poor mechanical properties [3-5]. As a polyheterocycle, polythiophene has rather poor mechanical properties. Nevertheless, polyheterocycles such as polythiophene, polypyrrole, and polyaniline have exhibited important improvements in oxidative stability. It has been demonstrated that composite structure using an insulating polymer as the host matrix improved the physical and chemical properties of the conducting polymer, particularly those already investigated such as polythiophene, polypyrrole and its derivatives [ 6$]$. The most conventional method to produce composite was found to be the electropolymerization of the thiophene monomer on an electrode coated with an insulating polymer, such as polyvinylchloride [78]. poly(bisphenol A carbonate) and polystyrene [9], polyamide[10].

In this study, conducting composites of polythiophene (PTh) with a synthetic rubber (SR) and a natural rubber (NR) wcrc prepared by electrochemical synthesis. The electrochemical behaviors of PTh, PTh/NR and PTh/SR composite films were studied by multiscan runs in order to compare the reversibility and reproducibility of the composites with those of the pure conducting polymer. Thermal behaviors of the composites were analyzed by recording mass spectra as a function of temperature under both direct and indirect pyrolysis MS conditions. The effect of each group on thermal stability of the other was investigated by comparing the thermal behaviors of composites with those of homopolymers. Pyrolysis analysis of PTh, NR and SR were also carried out for comparison.

\section{Experimental}

PTh and PTh/NR, PTh/SR composites were prepared by electronxidative polymerization of thiophene onto NR and SR coated $\mathrm{Pt}$ electrodes at a constant potential of $1.8 \mathrm{~V}$ versus $\mathrm{Ag}^{\circ} / \mathrm{AgBF}_{4}\left(10^{-2} \mathrm{M}\right)$ reference electrode. The working and counter electrodes were platinum bead and platinum wire respectively. TBAFB was used as the supporting electrolyte which had a concentration of $0.1 \mathrm{M}$. The electrolysis were achieved with a Wenking POS 73 potentiostat. The insulating rubher films were dip-coated from the toluene solution $\left(10 \mathrm{mgl}^{-1}\right)$ of Malezian based natural (Mol. Wt. about 1.500 .000 ) or synthetic (Mol. Wt. 1.000.000) rubber (cis-1,4-polyisoprene) [11]. The amounts of insulating and conducting polymers in the composites were determined gravimetrically.

Direct and indirect pyrolysis mass spectrometry analysis were achieved by a BALZERS QMG 311 quadrupole mass spectrometer controlled by a PC. Pyrolysis systems and their control units were designed in our laboratories. The details of the experimental setup were reported in our previous publication [12]. $0.1 \mathrm{mg}$ and $1.0 \mathrm{mg}$ samples were used in direct and indirect pyrolysis experiments respectively. The samples were heated to $120{ }^{\circ} \mathrm{C}$ rapidly and then heating rate was kept constant at $2^{\circ} \mathrm{C} / \mathrm{min}$ during the direct pyrolysis experiments. In the case of indirect pyrolysis the heating rate was $10^{\circ} \mathrm{C} / \mathrm{min}$.

\section{Results and Discussion}

The electrochemical behaviors of PTh and PTh/NR, PTh/SR composites were recorded. Fig.l a. shows the cyclic voltammogram of $\mathrm{PTh}$ at bare platinum electrode in the range of -0.20 and $2.10 \mathrm{~V}$. A peak for oxidation around $1.50 \mathrm{~V}$ on the anodic sweep and the corresponding reduction peak at around $1.15 \mathrm{~V}$ in the cathodic sweep. Multisweep CV of NR/PTh and SR/PTh electrodes are given in Fig. 1. b and c respectively. 
The oxidation peak is at $1.25 \mathrm{~V}$ and corresponding reduction peak is at $1.00 \mathrm{~V}$. Electroactivity of PTh is observed for the rubber coated electrodes which means that the NR and SR are sufficiently porous to allow thiophene and dopant ion to diffuse through rubbers. It has been observed that during electrolysis both NR and SR leave the Pt electrode to a certain extent.

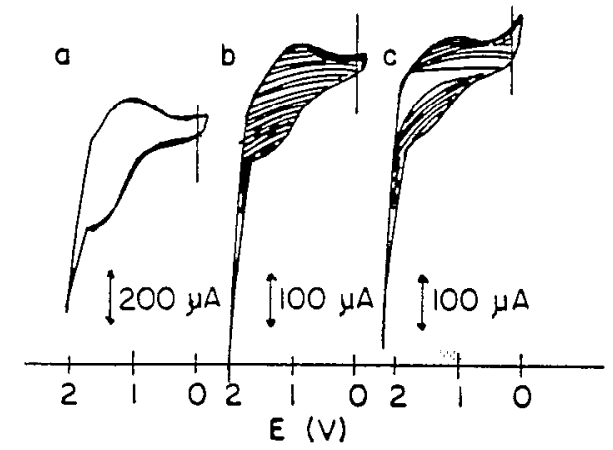

Fig. 1. Cyclic voltammogram of PTh a) bare b) NR coated c)SR coated Pt electrodes.

The data obtained by classical techniques such as FTIR, DSC and SEM were not sufficient to make any proposal about the structure of the composites. Thus pyrolysis experiments were carricd out for a better understanding. In Fig 2 direct pyrolysis mass spectra of PTh, NR and PTh/NR recorded at temperatures corresponding to maximum ion yield, namely at 210,219 and $174^{\circ} \mathrm{C}$ respectively, are given. SR and PTh/SR showed very similar pyrolysis mass spectra with NR and PTh/SR respectively. The disappearance of $N R$ and $S R$ based peaks in the corresponding composite mass spectra may be directly related to degradation of rubbers during polymerization. The composites were less stable and pyrolysis products were similar to those observed from PTh. Yet, presence of new fragments indicates presence of a chemical interaction between the two components of the composites.

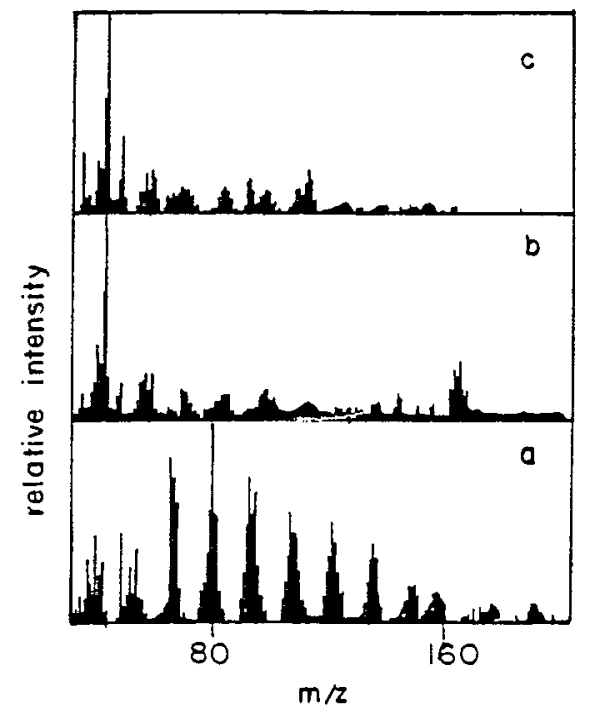

Fig. 2. Direct pyrolysis mass spectra of a) NR b) PTh and c) PTh/NR composite.

The maximum ion yield was observed at $230,370,375,257$ and $260{ }^{\circ} \mathrm{C}$ from PTh. NR, SR, PTh/NR and PTh/NR respectively, Indirect pyrolysis, evolved gas analysis were in accordance with direct pyrolysis results. Yet, in general only low molecular weight fragments were present .In Fig 3. indirect pyrolysis mass spectra of PTh, NR, PTh NR are given. Again rubber based peaks either appeared at low temperature ranges around $200^{\circ} \mathrm{C}$ or totally disappeared. It is clear from the pyrolysis data that decomposition of composites occur over a large temperature range as in the case of PTh. This may be related to either polydispersity of the polymers or to a crosslinked structure.

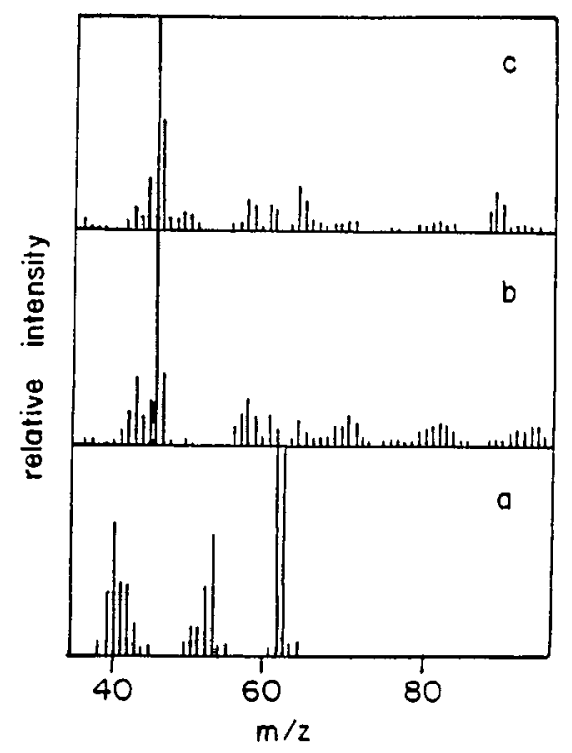

Fig. 3. Indirect pyrolysis mass spectra of a) NR b) PTh and c) PTh/NR composite

\section{Conclusion}

Degradation of rubbers during electrooxidative polymerization of thiophene using $N R$ and $S R$ coated $P t$ electrodes were confirmed by pyrolysis mass data. Furthermore evidences of chemical interaction formed between the components of the PThNR and PTh/S composites were determined.

\section{References}

[1] A.F. Diaz, K. K. Kanazawa, and G.P. Gardini.. J. Chem. Commun. (1979) 635.

[2] G. Torillion and F. Garnier, J.Electroanal. Chem. Interfacial. Electrochem., 135.(1987) 173.

[3] H. Lindenberger, D. Schafer-Siebert, S. Roth and H. Hanack. Synth. Met., 18 (1987) 37.

[4] M. Zagorcska, A. Pron, S. Lefrant, E. Kucharski, J. Suwalski and P. Bernier, Synth. Met ., 18 (1987)43.

[5] R. Quian, J. Qiu and D. Shen, Synth. Met., 18 (1987) 13.

[6] M.A. DePaoli, R.T. Waltman, A.F. Diaz and I: Bargon. J. Chem. Soc. Chem. Commun., (1984) 1015.

[7] N. Osamu, T. Tamamura, Synth. Met. , 20(1987) 235.

[8] J. Roncali, F. Garnier, J. Phys. Chem., 92 (1988) 833.

[9] H.L.Wang, L. Toppare, J.E. Fernandez, Macromolecules, 23 (1990) 1053.

[10]F. Vatansever, U. Akbulut, L. Toppare, and J. Hacaloglu Polymer, 37 (1996) 1103.

[11] S. Yigit, J. Hacaloglu, U. Akbulut and L. Toppare. 235. Synth. Met.79 (1996) I1.

[12]M.M. Fares, T. Yalcin, J. Hacaloglu, A. Güngör and S. Süzer, Analyst, 229 (1994) 63. 